\title{
Quality assessment of robot assisted thoracic surgical resection of non-small cell lung cancer: nodal upstaging and mediastinal recurrence
}

\author{
Ghada M. Shahin ${ }^{1}$, Besir Topal ${ }^{1}$, Sjaak Pouwels ${ }^{2}$, Thanasie L. Markou ${ }^{1}$, Rody Boon ${ }^{1}$, Jos A. Stigt ${ }^{3}$ \\ ${ }^{1}$ Department of Cardiothoracic Surgery, Isala Heart Center, Zwolle, The Netherlands; ${ }^{2}$ Department of Intensive Care, Elisabeth Tweesteden \\ Hospital, Tilburg, The Netherlands; ${ }^{3}$ Department of Pulmonology, Isala, Zwolle, The Netherlands \\ Contributions: (I) Conception and design: GM Shahin, B Topal, JA Stigt; (II) Administrative support: GM Shahin, B Topal, TL Markou, R Boon; (III) \\ Provision of study materials or patients: GM Shahin, TL Markou, R Boon; (IV) Collection and assembly of data: GM Shahin, B Topal, S Pouwels; (V) \\ Data analysis and interpretation: GM Shahin, B Topal, S Pouwels, JA Stigt; (VI) Manuscript writing: All authors; (VII) Final approval of manuscript: \\ All authors. \\ Correspondence to: Ghada M. Shahin, MD. Isala Heart Center, Dokter van Heesweg 2, 8025 AB Zwolle, The Netherlands. Email: gmmshahin@me.com.
}

Background: Robot assisted thoracic surgery (RATS) is the minimally invasive surgical technique of choice for treatment of patients with non-small cell lung cancer (NSCLC), at the Isala Hospital. The aim of this study is to compare clinical and pathological staging results and mediastinal recurrence after RATS for anatomical resections of lung cancer as surrogate markers for quality of mediastinal lymph node dissection (MLND).

Methods: This single institute retrospective study was conducted in patients who underwent RATS for NSCLC. Excluded were patients with a history of concurrent malignant disease, with other previous neoplasms, with small cell lung cancer (SCLC) and patients in whom the robotic technique was converted to thoracotomy, prior to lymph node dissection. Data were obtained from the hospital database. The difference between clinical and pathological staging was expressed as upstaging and downstaging. Computed Tomography scanning was used for follow-up, and diagnosis of mediastinal recurrence.

Results: From November 2011 to May 2016, 227 patients underwent RATS at Isala Hospital Zwolle, the Netherlands. Of those, 130 (mean age, 69.5 \pm 9.3 years) met the eligibility criteria. Preoperative mediastinal lymph node staging was done by endoscopic ultrasound/endobronchial ultrasound, by positron emission tomography (PET) or mediastinoscopy. In 14 patients (10.8\%) unforeseen N2 disease was found, 6 patients $(4.6 \%)$ were upstaged from $\mathrm{cN} 0$ to $\mathrm{pN} 2$ and 8 patients $(6.2 \%)$ were upstaged from cN1 to pN2. Mediastinal recurrence was detected in 7 patients (5.4\%) during a median follow-up of 54 months (range, 1.5-102 months).

Conclusions: In patients with NSCLC, who underwent anatomical resection by means of RATS, an unforeseen N2 disease rate of $10.8 \%$ was demonstrated and a mediastinal recurrence rate of $5.4 \%$. It is concluded that robotic surgery provides an accurate lymph node dissection.

Keywords: Non-small cell lung cancer (NSCLC); robot assisted thoracic surgery (RATS); lymph node dissection; mediastinal recurrence

Submitted Jun 21, 2020. Accepted for publication Nov 22, 2020.

doi: $10.21037 /$ jtd-20-2267

View this article at: http://dx.doi.org/10.21037/jtd-20-2267 


\section{Introduction}

Surgical resection remains the standard treatment of early stage non-small cell lung cancer (NSCLC) (1-3). Minimally invasive approaches such as multi-and uniportal video assisted thoracoscopic surgery (VATS) and 3-4 arm robot assisted thoracic surgery (RATS) are alternatives to thoracotomy. VATS is widely established in The Netherlands, but the application of robotic thoracic surgery has been rather stagnant, mainly due to financial issues and the new technical challenge that accompanies it (4-12).

After executing a vast experience in VATS, the technique of preference in lung surgery has shifted towards RATS at the Isala Hospital. This resulted from the benefits, such as the high-definition 3-dimensional view, the surgeonoperated camera, the increased freedom of intrathoracic movement, the scaled-down motion and the hand-related tremor filtration (13-15).

These features of RATS technology enable precise hilar and mediastinal lymph node dissection (MLND), which is a major prognostic factor in NSCLC (16). Even in case of preoperative invasive mediastinal staging, it is recommended that $\geq 3$ ipsilateral MLN (N2) stations should be dissected, in addition to regional LN (N1) stations (17).

Although there is an ongoing debate on the "best" minimally invasive technique regarding MLND or sampling there is agreement that all thoracic surgical units should have access or expertise to either VATS or RATS. Thoracotomy in early stage lung cancer should to be avoided. Either way, the ultimate goal ought to be the pursuit of radical resection along with the most precise staging possible.

The hypothesis of this study is that the surgical accuracy facilitated by a robotic platform, results, not only in a higher yield of lymph nodes, but also a more precise and complete lymph node dissection. Therefore, the specific objective of this single center study was to assess the quality of RATS lymph node dissection, expressed by the surrogate markers of pathological upstaging and mediastinal recurrence.

We present the following article in accordance with the STROBE reporting checklist (available at http://dx.doi. org/10.21037/jtd-20-2267).

\section{Methods}

Key element of the study design is a single institutional retrospective cohort study of patients with NSCLC operated on by RATS. The setting is the Department of
Cardiothoracic Surgery at the Isala Hospital in Zwolle The Netherlands. This is a tertiary non-academic hospital. The database of the Department of Cardiothoracic Surgery and Intensive Care of the Isala Hospital was used for data collection. Patients who were operated on between November 2011 and May 2016 were selected for eligibility. Follow-up data were collected from the same database. For this retrospective human study the Medical Ethical Research Board was consulted. It concluded that no ethical approval was required as all data were collected from the same database for which the patients had given their consent. The study was conducted in accordance with the Declaration of Helsinki (as revised in 2013).

The eligibility criteria were patients with histologically proven NSCLC, who underwent anatomic resection by means of RATS. We excluded patients with a history of concurrent malignant disease or other previous primary neoplasms $(\mathrm{N}=25)$, patients with small cell lung cancer (SCLC) $(\mathrm{N}=1)$, patients in whom the operation was converted to thoracotomy, before $\mathrm{LN}$ dissection was carried out $(\mathrm{N}=23)$, and a variety of other pathology $(\mathrm{N}=48)$. Of the initially selected 227 patients, 130 remained to be analyzed for this study (Figure 1). For the postoperative follow-up of the patients CT scanning was used. Unfortunately, intervals for performing the CT scan were not predefined. Patients were included until May 2016 in order to achieve a longterm follow-up.

Outcomes were defined as nodal upstaging and mediastinal recurrence. Nodal upstaging was assessed by comparing the cTNM to the pTNM. Preoperative staging was based on integrated fluor-18-deoxyglucose positron emission tomography (FDG-PET) and computed tomographic (CT) scans, and endoscopic ultrasonography and/or endobronchial (EUS/EBUS), and mediastinoscopy $(18,19)$. Lymph nodes were considered clinically positive when the short-axis diameter was $\geq 1 \mathrm{~cm}$ on CT or when $\mathrm{SUV}_{\text {max }} \geq 2.5$ on PET scan. Routinely, all lymph node stations were examined by EBUS in case of hilar involvement and centrally located tumors. Mediastinoscopy was only performed when during EUS/EBUS no representative lymphatic tissue could be retrieved in patients with high suspicion of mediastinal metastatic disease. Upstaging was defined as a higher pTNM than cTNM classification. Downstaging was defined as a lower pTNM than the cTNM as described preoperatively. Unforeseen $\mathrm{N} 2$ disease (cN0/N1-to-pN2) is defined as patients with $\mathrm{N} 0$ or $\mathrm{N} 1$ in whom postoperative histological mediastinal involvement (N2) was determined. 


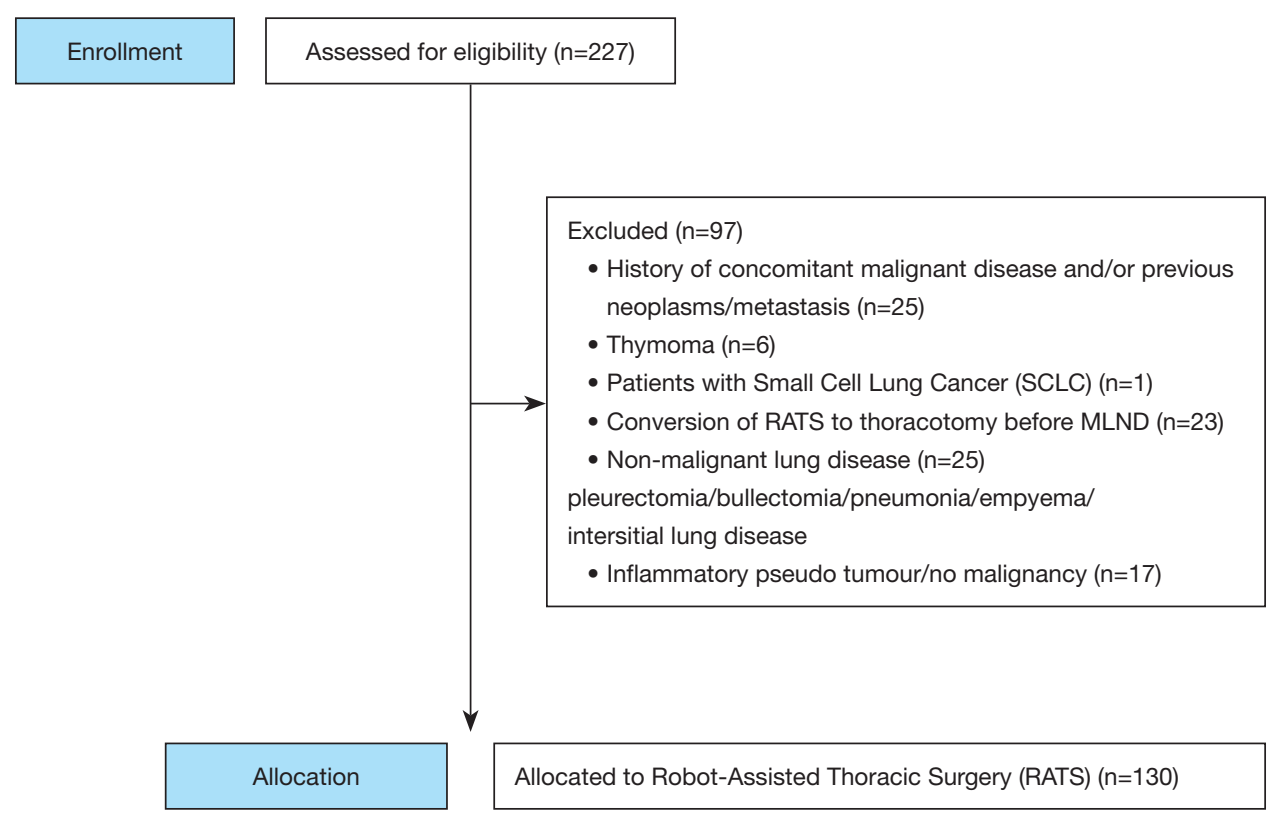

Figure 1 Patient selection.

Mediastinal recurrence was defined as pathologically proven or strong suggestion of imaging of tumor recurrence on follow-up CT within MLN stations.

Data were collected on localization of primary tumor (peripheral/central), lymph node stations dissected (IASLC location, cTNM and pTNM, stage, number of unforeseen $\mathrm{N} 2$ nodes and mediastinal recurrence), as well as the rate of conversion to thoracotomy prior to lymph node dissection.

\section{Statistical analysis}

All data were analyzed retrospectively. Data management and analysis was performed using SPSS version 23 for Windows (IBM Corporation, Armonk, NY, USA). Continuous variables were presented as mean \pm standard deviation $(\mathrm{SD})$. Mean, standard error of the mean, and range were used for age and LN stations. Categorical data were expressed as count (\%). The rate of nodal upstaging/downstaging and the rate of mediastinal recurrence on CT are expressed as count (\%). P values $\leq 0.05$ were considered statistically significant.

The surgical technique that was used was the 4-arm complete portal robotic lobectomy: CPRL-4, together with $\mathrm{CO}_{2}$ insufflation (20). The robotic platform that was used is the Intuitive Surgical Da Vinci ${ }^{\circledR} \mathrm{Si}$, (Intuitive Surgical Inc., Sunnyvale, California, USA). According to the Cancer and Leukemia Group B (CALGB) 39802-consensus report for VATS lobectomy we adhered in all cases to the use of non-rib spreading incisions, with the largest incision no greater than $8 \mathrm{~cm}$ (21). Lymph node dissection was carried out for stations 2, 4, 7, 8, 9, 10 and 11 on the right side, and 5, 6, 7, 8, 9, 10, 11 on the left side, according the International Association for the Study of Lung Cancer (IASLC) (22). All stations were dissected en bloc with the surrounding fatty tissue.

Although all surgical procedures were performed by one surgeon and the surgical technique is therefore reproducible, we are aware that the preoperative staging, by means of EUS/EBUS or mediastinoscopy, might be a potential source of bias.

Postoperative pathologic staging was determined by examination of intraoperative dissected lymph node stations. Clinical and pathological staging was determined according to the IASLC proposal (22).

Postoperative follow-up data were obtained from $116(89.2 \%)$ of patients. In the majority follow-up was ascertained by means of a CT or PET-CT. The data of the 14 patients who were lost to follow-up, were sought for extensively, yet unfortunately could not be retrieved from the archives of referring hospitals. They were not included in the analysis.

\section{Results}

Between November 2011 and May 2016, 227 patients underwent RATS at the Isala Hospital in Zwolle, The 
Table 1 Patient characteristics and disease classification

\begin{tabular}{|c|c|}
\hline Characteristics & Number \\
\hline Age (in years) & $69.5 \pm 9.3$ \\
\hline Gender (M:F) & 77 (59.2\%):53 (40.8\%) \\
\hline \multicolumn{2}{|l|}{ Histology } \\
\hline Adenocarcinoma & $73(56.1 \%)$ \\
\hline Squamous & $38(29.2 \%)$ \\
\hline Neuroendocrine & $7(5.4 \%)$ \\
\hline Other NSCLC & $12(9.3 \%)$ \\
\hline \multicolumn{2}{|l|}{ Tumor location } \\
\hline Central & $35(26.9 \%)$ \\
\hline Peripheral & $83(63.9 \%)$ \\
\hline Central and peripheral & $12(9.2 \%)$ \\
\hline \multicolumn{2}{|l|}{ Clinical stage/pathological stage } \\
\hline Stage IA & $57(43.8 \%) / 50(38.4 \%)$ \\
\hline Stage IB & $26(20.0 \%) / 23(17.7 \%)$ \\
\hline Stage IIA & $24(18.5 \%) / 21(16.2 \%)$ \\
\hline Stage IIB & $15(11.5 \%) / 13(10.0 \%)$ \\
\hline Stage IIIA & $4(3.1 \%) / 19(14.6 \%)$ \\
\hline Stage IIIB & $0(0.0 \%)$ \\
\hline Stage IV & $4(3.1 \%) / 4(3.1 \%)$ \\
\hline \multicolumn{2}{|l|}{$\begin{array}{l}\text { Preoperative MLN staging } \\
\text { technique }\end{array}$} \\
\hline PET & $3(2.3 \%)$ \\
\hline $\mathrm{CT}+\mathrm{PET}-\mathrm{CT}$ & $77(59.2 \%)$ \\
\hline $\mathrm{CT}+\mathrm{PET}-\mathrm{CT}+\mathrm{EUS} / \mathrm{EBUS}$ & $49(37.7 \%)$ \\
\hline CT + PET-CT + mediastinoscopy & $1(0.8 \%)$ \\
\hline \multicolumn{2}{|l|}{ Type of FU imaging } \\
\hline X-thorax & $16(12.3 \%)$ \\
\hline CT & $57(43.8 \%)$ \\
\hline PET-CT & $33(25.4 \%)$ \\
\hline Missing or not applicable & $24(18.5 \%)$ \\
\hline \multicolumn{2}{|l|}{ Recurrence on imaging } \\
\hline No recurrence & $75(57.7 \%)$ \\
\hline Mediastinal recurrence & $7(5.4 \%)$ \\
\hline Local metastases & $19(14.6 \%)$ \\
\hline Distant metastases & $10(7.7 \%)$ \\
\hline
\end{tabular}

M, male; F, female; MLN, mediastinal lymph node; FU, followup.
Table 2 Type of resection and surgical specimen

\begin{tabular}{lc}
\hline Variables & Number \\
\hline Type of resection & $112(86.2 \%)$ \\
Lobectomy & $6(4.6 \%)$ \\
Segmentectomy (3 RUL, 1 RLL, 2 LUL) & $4(3.1 \%)$ \\
Bilobectomy (3 RML + RLL, 1 RML + RUL) & $8(6.2 \%)$ \\
Pneumonectomy (5 right, 3 left) & \\
Lobe & $38(29.2 \%)$ \\
RUL & $13(10.0 \%)$ \\
RML & $28(21.5 \%)$ \\
RLL & $34(26.2 \%)$ \\
LUL & $17(13.1 \%)$ \\
LLL & \\
\hline
\end{tabular}

RUL, right upper lobe; RML, right middle lobe; RLL, right lower lobe; LUL, left upper lobe; LLL, left lower lobe; MLND, mediastinal lymph node dissection.

Netherlands. All were examined for eligibility. As shown in Figure 1, 130 patients met the inclusion criteria. These 130 patients were included in the study.

Table 1 gives an overview of the patient characteristics. The rationale to include stage IV patients is that these are patients with oligometastatic disease, for whom was decided to surgically remove the primary NSCLC and administer radiotherapy for the metastasis.

Table 2 shows the type of resection and the resected specimen.

The anatomic locations of the tumors and the type of resection as well as the amount of obtained lymph nodes are summarized in Tables 2 and 3.

After robotic MLND the operation was converted to thoracotomy in $3.1 \%$.

As is shown in Table 4, the clinical stage did not alter postoperatively in 69 patients $(53.1 \%)$.

There was upstaging in $36.1 \%$ of patients, either by tumor size $(\mathrm{T})$ or by nodal status $(\mathrm{N})$.

Nodal upstaging was found in 26 patients $(20 \%)$ of which, 9.2\% upstaging from $\mathrm{cN} 0-\mathrm{pN} 1,4.6 \% \mathrm{cN} 0-\mathrm{pN} 2$ (skip $\mathrm{N} 2$ ) and $6.2 \%$ from $\mathrm{cN} 1$ to $\mathrm{pN} 2$, which explains the $10.8 \%$ unforeseen N2 disease. To correlate this finding with the pre-operative staging, the medical records were revisited. In 8 of the 14 upstaged patients, pre-operative EUS/EBUS was performed as planned. In 1 patient, the procedure was aborted due to technical difficulties. In the 
seven completed EUS/EBUS procedures, there was an adequate yield of lymphatic tissue.

Four patients did not undergo a preoperative EUS/ EBUS and the staging of the mediastinum was based entirely on imaging by means of CT and PET CT scan. Lastly, one of the fourteen upstaged patients, underwent a (false negative) mediastinoscopy.

Nodal downstaging was found in 4 patients $(3.1 \%)$,

Table 3 Harvested lymph nodes, levels and stations

\begin{tabular}{lc}
\hline Variables & Number \\
\hline Level of lymph nodes, mean \pm SD & \\
Level N1 & $2.0 \pm 0.59$ \\
Level N2 & $3.6 \pm 1.2$ \\
Levels N1+N2 & $5.6 \pm 1.4$ \\
Stations of lymph nodes & \\
N2 & $58(44.6 \%)$ \\
N4 & $64(49.2 \%)$ \\
N5 & $42(32.3 \%)$ \\
N6 & $42(32.3 \%)$ \\
N7 & $124(95.4 \%)$ \\
N8 & $81(62.3 \%)$ \\
N9 & $59(45.4 \%)$ \\
N10 & $110(84.6 \%)$ \\
N11 & $119(91.5 \%)$ \\
N12 & $21(16.2 \%)$ \\
Patients with N1 and/or N2 metastases & $26(20 \%)$ \\
Patients with unforeseen N2 disease & $14(10.8 \%)$ \\
\hline N12 regional lymph nodes; N2, mediastinal lymph nodes. N2- \\
from Naruke's lymph node chart. \\
\end{tabular}

which can be explained by a successful neoadjuvant chemoradiation therapy (Table 4).

Median postoperative follow-up period of 116 patients (89.2\%) was 54 months, range 1.5-102 months. In seven patients $(5.4 \%)$ mediastinal recurrence was detected.

\section{Discussion}

The present retrospective single center study reports on unforeseen $\mathrm{N} 2$ disease and mediastinal recurrence as parameters of quality of robot assisted anatomical resection for NSCLC. Nodal upstaging from $\mathrm{cN} 0 / \mathrm{N} 1$ to $\mathrm{pN} 2$ was found in $10.8 \%$ with a skip N2 metastasis rate of $4.6 \%$ of the 130 investigated patients. Mediastinal recurrence during a median follow-up of 54 months was found in $5.4 \%$ of the patients. Both parameters are considered to be surrogate markers for the quality of RATS MLND.

For the accuracy of staging NSCLC, only little evidence is provided to support the superiority of MLND over lymph node sampling. However, although not supported by randomized controlled trials, retrospective cohort studies comparing MLND with lymph node sampling in stage I disease, suggest a survival benefit after MLND (23). This is not surprising, as a more thorough exploration of mediastinal nodes will more frequently result in detection of stage migration to higher levels.

The question rises if the superior operating features of RATS are distinctive enough to show better result when compared with VATS. The rate of unforeseen N2 disease and mediastinal recurrence rate might be regarded as reflections of a technique's superiority in mediastinal lymph node examination.

First, the unforeseen N2 rate of $10.8 \%$ with RATS in our study is comparable to studies composed of similar cohorts (stages I-IV) reporting rates of $8.4 \%$ up to $10.7 \%(24,25)$. Lower rates of unforeseen N2 disease of $4.3 \%$ and $6 \%$ are reported with RATS in stage I disease $(26,27)$. When

Table 4 Up-and downstaging from clinical to pathologic status

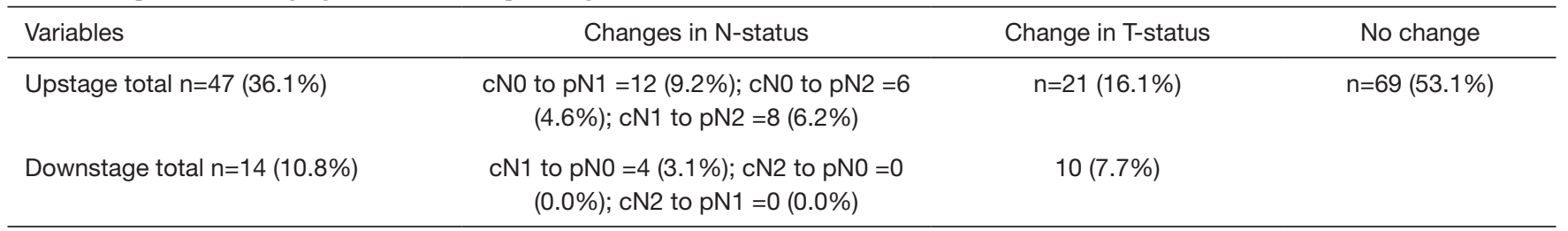

cN0, clinical stage without lymph node metastasis; cN1, clinical stage with regional lymph node metastasis; cN2, clinical stage with mediastinal lymph node metastasis; pNO, pathologic stage without lymph node metastasis; pN1, pathologic stage with regional lymph node metastasis; pN2, pathologic stage with mediastinal lymph node metastasis. 
comparing unforeseen N2-rates of VATS with thoracotomy most studies reports differences in favor of thoracotomy. Rates range from $1.8-4.9 \%$ in VATS to $5.0-11.5 \%$ in thoracotomy (28-31). Robotic surgery, yielded more lymph nodes compared to thoracotomy in clinical stage I disease without influencing survival (32). Unforeseen N2 rates are not mentioned in this report.

Secondly, the local recurrence rate of $5.4 \%$ as observed with RATS in our report is in line with results reported in former studies. A locoregional recurrence rate (hilar and mediastinal recurrence) with VATS for clinical stage I and II disease is demonstrated in 8 patients out of a series of 248 procedures $(3.2 \%)(33,34)$. A similar defined local recurrence rate of $9.4 \%$ is reported in a series of 1012 VATS procedures for stages I-III (35).

\section{Limitations of the study}

The sample size of this study is small. The inclusion for analysis was halted in May 2016, in order to accomplish a long-term follow-up. Due to the retrospective design of this study, we have a number of missing follow-up data. Followup is complete for $89.2 \%$, which might have resulted in an underrated mediastinal recurrence rate. Furthermore, there was no standardization concerning the preoperative lymph node staging, this has currently improved. In this study the clinical staging was determined by variations in technical skills of the pulmonologists who perform the EUS/EBUS. Mediastinoscopy should be performed more frequently, and an insufficient yield of lymphatic tissue during EUS/EBUS should not be accepted.

Another limitation might be the fact that we analyzed patients in various stages of NSCLC. It is to be expected that the higher stages of the disease will result more frequently and/or faster in mediastinal and locoregional recurrence.

We have included both pneumonectomy and segmentectomy patients. Although theoretically the biologic behavior of large or centrally located tumors requiring pneumonectomy is different from small peripheral tumors for which segmentectomy is sufficient, we focus in this manuscript on the feasibility and accuracy of lymph node dissection. As the lymph node dissection was performed in the same standardized fashion in every resection, we decided to include all types of resections.

As future perspective, we suggest studies that are designed to ascertain the correlation between surgical nodal upstaging, mediastinal recurrence and thus survival. A more accurate and standardized preoperative mediastinal staging and follow-up by means of CT scanning in all patients at preset intervals is desirable.

\section{Conclusions}

In this retrospective study, RATS lymph node dissection in patients undergoing lung resection for NSCLC stages I-IV resulted in $10.8 \%$ unforeseen N2 disease rate, and $5.4 \%$ mediastinal recurrence at a median follow-up time of 54 months (mean 42.8 months, range, 1.5-102 months). Regarding the advocated advantages of VATS and RATS concerning unexpected N2 disease and local recurrence after MLND, it will be difficult to prove superiority for one of the techniques. However, the presented results support earlier reports on the accuracy of RATS.

Superiority of RATS might be sought in other fields, such as expansion of the indications for minimally invasive surgical approach.

\section{Acknowledgments}

The authors would like to thank R.M. Brohet, for the statistical analysis of the data, and cardiothoracic surgeons Dr. G.J. Brandon Bravo Bruinsma and Dr. S. Siddiqi for their feedback and critical reading of this manuscript.

Funding: None.

\section{Footnote}

Reporting Checklist: The authors have completed the STROBE reporting checklist. Available at http://dx.doi. org/10.21037/jtd-20-2267

Data Sharing Statement: Available at http://dx.doi. org/10.21037/jtd-20-2267

Conflicts of Interest: All authors have completed the ICMJE uniform disclosure form (available at http://dx.doi. org/10.21037/jtd-20-2267). GMS reports that she is proctor for Intuitive Surgical Inc. The other authors have no conflicts of interest to declare.

Etbical Statement: The authors are accountable for all aspects of the work in ensuring that questions related to the accuracy or integrity of any part of the work are appropriately investigated and resolved. For this retrospective human study, the Medical Ethical Research 
Board was consulted. It concluded that no ethical approval was required as all data were collected from the same database for which the patients had given their consent. The study was conducted in accordance with the Declaration of Helsinki (as revised in 2013).

Open Access Statement: This is an Open Access article distributed in accordance with the Creative Commons Attribution-NonCommercial-NoDerivs 4.0 International License (CC BY-NC-ND 4.0), which permits the noncommercial replication and distribution of the article with the strict proviso that no changes or edits are made and the original work is properly cited (including links to both the formal publication through the relevant DOI and the license). See: https://creativecommons.org/licenses/by-nc-nd/4.0/.

\section{References}

1. Scott WJ, Howington J, Feigenberg S, et al. Treatment of non-small cell lung cancer stage I and stage II: ACCP evidence-based clinical practice guidelines (2nd edition). Chest 2007;132:234S-242S.

2. Howlader N, Noone AM, Krapcho M, et al. editors. National Cancer Institute Bethesda, MD. Available online: https://seer.cancer.gov/csr/1975_2017 SEER Cancer Statistics Review 1975-2017.

3. Raman V, Yang CJ, Deng JZ, et al. Surgical treatment for early stage non-small cell lung cancer. J Thorac Dis 2018;10:S898-S904.

4. Walker WS, Casali G. The VATS lobectomist: analysis of costs and alterations in the traditional surgical working pattern in the modern surgical unit. Thorac Surg Clin 2008; 18:281-7.

5. Begum S, Hansen HJ, Papagiannopoulos K. VATS anatomic lung resections-the European experience. J Thorac Dis 2014;6 Suppl 2:S203-10.

6. Gjeraa K, Mundt AS, Spanager L, et al. Important NonTechnical Skills in Video-Assisted Thoracoscopic Surgery Lobectomy: Team Perspectives. Ann Thorac Surg 2017;104:329-35.

7. Jensen K, Petersen RH, Hansen HJ, et al. A novel assessment tool for evaluating competence in videoassisted thoracoscopic surgery lobectomy. Surg Endosc 2018;32:4173-82.

8. Petersen RH, Gjeraa K, Jensen K, et al. Assessment of competence in video-assisted thoracoscopic surgery lobectomy: A Danish nationwide study. J Thorac Cardiovasc Surg 2018;156:1717-22.
9. Mahtabifard A, DeArmond DT, Fuller CB, et al. Videoassisted thoracoscopic surgery lobectomy for stage I lung cancer. Thorac Surg Clin 2007;17:223-31.

10. McKenna RJ Jr. Surgical management of primary lung cancer. Semin Oncol 2007;34:250-5.

11. McKenna RJ Jr. Complications and learning curves for video-assisted thoracic surgery lobectomy. Thorac Surg Clin 2008;18:275-80.

12. Guido-Guerrero W, Bolanos-Cubillo A, GonzalezRivas D. Single-port video-assisted thoracic surgery (VATS)-advanced procedures \& update. J Thorac Dis 2018;10:S1652-61.

13. Mazzei M, Abbas AE. Why comprehensive adoption of robotic assisted thoracic surgery is ideal for both simple and complex lung resections. J Thorac Dis 2020;12:70-81.

14. Ricciardi S, Cardillo G, Zirafa CC, et al. Robotic lobectomies: when and why? J Vis Surg 2017;3:112.

15. Ricciardi S, Zirafa CC, Davini F, et al. How to get the best from robotic thoracic surgery. J Thorac Dis 2018;10:S947-50.

16. Asamura H, Chansky K, Crowley J, et al. The International Association for the Study of Lung Cancer Lung Cancer Staging Project: Proposals for the Revision of the $\mathrm{N}$ Descriptors in the Forthcoming 8th Edition of the TNM Classification for Lung Cancer. J Thorac Oncol 2015;10:1675-84.

17. Wang Y, Darling GE. Complete mediastinal lymph node dissection versus systematic lymph node sampling in surgical treatment of non-small cell lung cancer: do we have the answer? J Thorac Dis 2017;9:4169-70.

18. De Leyn P, Dooms C, Kuzdzal J, et al. Revised ESTS guidelines for preoperative mediastinal lymph node staging for non-small-cell lung cancer. Eur J Cardiothorac Surg 2014;45:787-98.

19. De Leyn P, Dooms C, Kuzdzal J, et al. Preoperative mediastinal lymph node staging for non-small cell lung cancer: 2014 update of the 2007 ESTS guidelines. Transl Lung Cancer Res 2014;3:225-33.

20. Cerfolio RJ, Bryant AS, Skylizard L, et al. Initial consecutive experience of completely portal robotic pulmonary resection with 4 arms. J Thorac Cardiovasc Surg 2011;142:740-6.

21. Swanson SJ, Herndon JE 2nd, D'Amico TA, et al. Videoassisted thoracic surgery lobectomy: report of CALGB 39802--a prospective, multi-institution feasibility study. J Clin Oncol 2007;25:4993-7.

22. Goldstraw P, Chansky K, Crowley J, et al. The IASLC Lung Cancer Staging Project: Proposals for Revision of the TNM Stage Groupings in the Forthcoming (Eighth) 
Edition of the TNM Classification for Lung Cancer. J Thorac Oncol 2016;11:39-51.

23. Mitsos S, Panagiotopoulos N, Patrini D, et al. Is systematic lymph node dissection mandatory or is sampling adequate in patients with stage I non-small-cell lung cancer? Interact Cardiovasc Thorac Surg 2019;28:550-4.

24. Velez-Cubian FO, Rodriguez KL, Thau MR, et al. Efficacy of lymph node dissection during robotic-assisted lobectomy for non-small cell lung cancer: retrospective review of 159 consecutive cases. J Thorac Dis 2016;8:2454-63.

25. Toosi K, Velez-Cubian FO, Glover J, et al. Upstaging and survival after robotic-assisted thoracoscopic lobectomy for non-small cell lung cancer. Surgery 2016;160:1211-8.

26. Wilson JL, Louie BE, Cerfolio RJ, et al. The prevalence of nodal upstaging during robotic lung resection in early stage non-small cell lung cancer. Ann Thorac Surg 2014;97:1901-6; discussion 1906-7.

27. Park BJ. Robotic lobectomy for non-small cell lung cancer: long-term oncologic results. Thorac Surg Clin 2014;24:157-62, vi.

28. Boffa DJ, Kosinski AS, Paul S, et al. Lymph node evaluation by open or video-assisted approaches in 11,500 anatomic lung cancer resections. Ann Thorac Surg 2012;94:347-53; discussion 353.

29. D'Amico TA, Niland J, Mamet R, et al. Efficacy of mediastinal lymph node dissection during lobectomy

Cite this article as: Shahin GM, Topal B, Pouwels S, Markou TL, Boon R, Stigt JA. Quality assessment of robot assisted thoracic surgical resection of non-small cell lung cancer: nodal upstaging and mediastinal recurrence. J Thorac Dis 2021;13(2):592-599. doi: 10.21037/jtd-20-2267 for lung cancer by thoracoscopy and thoracotomy. Ann Thorac Surg 2011;92:226-31; discussion 231-2.

30. Merritt RE, Hoang CD, Shrager JB. Lymph node evaluation achieved by open lobectomy compared with thoracoscopic lobectomy for N0 lung cancer. Ann Thorac Surg 2013;96:1171-7.

31. Licht PB, Jorgensen OD, Ladegaard L, et al. A national study of nodal upstaging after thoracoscopic versus open lobectomy for clinical stage I lung cancer. Ann Thorac Surg 2013;96:943-9; discussion 949-50.

32. Yang HX, Woo KM, Sima CS, et al. Long-term Survival Based on the Surgical Approach to Lobectomy For Clinical Stage I Nonsmall Cell Lung Cancer: Comparison of Robotic, Video-assisted Thoracic Surgery, and Thoracotomy Lobectomy. Ann Surg 2017;265:431-7.

33. Haruki T, Miwa K, Araki K, et al. Distribution and Prevalence of Locoregional Recurrence after VideoAssisted Thoracoscopic Surgery for Primary Lung Cancer. Thorac Cardiovasc Surg 2016;64:526-32.

34. Falcoz PE, Massard G. Locoregional recurrence after VATS surgery for NSCLC. J Thorac Dis 2016;8:E1694-6.

35. Isaka $M$, Kojima $H$, Takahashi $S$, et al. Risk factors for local recurrence after lobectomy and lymph node dissection in patients with non-small cell lung cancer: Implications for adjuvant therapy. Lung Cancer 2018;115:28-33. 